\title{
Do we experience a prisoner's dilemma when choosing to wear a face mask?
}

\author{
Emmanuel ARIS ${ }^{1}$
}

${ }^{1} \mathrm{NA}$

May 13, 2020

To the Editor,

Is it worth wearing a face mask? That is the question many people ask during the COVID-19 pandemic. To better understand answers of individuals to this question and their subsequent risk, we first recall the prisoner's dilemma, a classic example of Game Theory, and then apply the same ideas to the decision of wearing a face mask.

In the prisoner's dilemma, two individuals, A and B, are arrested and put in a solitary confinement being both suspected of a robbery. ${ }^{1}$ Each of the prisoners has a choice between either testifying that the other committed the crime, or remaining silent. The prosecutor comes with the following offer to each prisoner separately: if you testify and the other remains silent, you will be free and the other will be imprisoned for three years, and vice versa. However, if you both testify, you will both get two years of imprisonment. Finally, if you both remain silent, you get one year each. At the personal level, testifying that the other did it is more interesting than remaining silent: if the other prisoner remains silent, testifying will get you free; if he testifies, testifying will result in two years in prison instead of three. Therefore, the two prisoners will tend to testify against each other and will get two years of imprisonment each. Meanwhile, if they had both cooperated and remained silent, they would both have ended up in a better situation as they would have been sentenced to one year of imprisonment instead of two.

Consider now a group of $N+1$ individuals among whom contact patterns and disease transmission are the same in a situation where there is sustained human-to-human infection. Here, we are looking at the consequences of getting infected $(\mathrm{P})$ if an individual $i$ decides to wear a mask or not, and the effort (E) needed to get and wear the mask. Let $\mathrm{C}_{0}$ be the risk of $i$ getting infected when all other $N$ individuals wear a mask, and $\delta_{1}, \delta_{2}, \ldots, \delta_{N}$, the additional risk of getting infected when $1,2, \ldots, N$ subjects don't wear a mask. Denote the percentage of protection obtained when wearing a mask by $\varepsilon$. The probability of $i$ being infected and the effort needed when deciding to wear a mask or not, can be formulated as shown in Table 1.

When, for example, $r$ individuals do not wear a mask, if $i$ decides to wear a mask, the effort $f$ needed for this decision results in a decreased risk of infection is $\left(\mathrm{C}_{0}+\delta_{\mathrm{r}}\right) \epsilon$. Weighing this gain against the effort helps in choosing whether to wear a mask or not.

At the individual level, $i$ may well be tempted not to wear a mask: for non-surgical masks the gain $\left(\mathrm{C}_{0}+\delta\right.$ r) $\epsilon$ can be low, as the level of protection can be small against submicron particles. ${ }^{2}$ In addition, if improperly manipulated, masks may even increase the risk of contamination. ${ }^{3}$ Finally, COVID-19 infection was reported to also happen via the eyes which are not covered by the mask. ${ }^{4}$ All this while a substantial effort $f$ may be needed to be able to manage the discomfort and proper handling of the mask.

However, if all the other individuals, reasoning like $i$, also decide not to wear masks the resulting risk of getting infected becomes $\mathrm{C}_{0}+\delta_{N}$. This would mean an increase of $\mathrm{C}_{0} \epsilon+\delta_{N}$ in infection risk compared 
to the situation where everyone wore a mask. The addition of $\delta_{N}$ to the reduction in infection risk can justify wearing a mask as $\delta_{N}$ is likely to be nonnegligible: if everybody, including the infected ones who are asymptomatic, but infectious, were wearing a mask, this could significantly reduce the virus transmission..$^{\mathbf{5 , 6 , 7}}$ In fact, the indirect protective effect of everybody else wearing a mask on decreasing the infection risk $\delta_{N}$ may be much higher than the direct protective effect $\left(\mathrm{C}_{0}+\delta_{\mathrm{r}}\right) \epsilon$ of wearing a mask.

Other factors may influence the decision of whether to wear or not a mask, but it is unlikely that the protective aspects and the burden linked to their use would not play significant roles in the decision of wearing them. Given a potentially weak protective effect, a significant effort needed to wear them, and a marked disease containment indirect effect, we may well end up in a prisoner's dilemma situation. The question is then how to bring the individuals to cooperate and reach the optimal situation of wearing masks. Several options can be considered, spanning from simple encouragement to enforcement. Educating the public by explaining the benefit of everybody wearing even imperfectly sealed masks could provide a potentially cheap and effective measure. ${ }^{8}$ Another option could be to lower the effort $f$ by making good quality and easy to use masks widely available. These initiatives along with other incentives to foster a cooperative behaviour amongst individuals could be key to achieve widespread use of masks to fight against the COVID-19 pandemic, especially when easing lockdown restrictions.

\section{Disclaimer}

Emmanuel Aris is currently employed by GSK, but wrote this article in his personal capacity. The views expressed are his own and do not necessarily represent the views of GSK.

\section{References}

1. Nash J. Non Cooperative Games. Annals of Mathematics 1951;54: 286-295. DOI: 10.2307/1969529.

2. Rengasamy S, Eimer B, Shaffer RE. Simple Respiratory Protection-Evaluation of the Filtration Performance of Cloth Masks and Common Fabric Materials Against 20-1000 nm Size Particles. Ann. Occup. Hyg. 2010; 54:789-798. DOI: 10.1093/annhyg/meq044. Epub 2010 Jun 28.

3. World Health Organization. Advice on the use of masks in the community setting in Influenza A (H1N1) outbreaks. Interim guidance (3 May 2009). http://www.who.int/csr/resources/publications/Adviceusemaskscommunityrevised.pdf Date: 2020. Accessed April 20th 2020.

4. Li JPO, Lam DSC, Chen Y, et al . Novel Coronavirus disease 2019 (COVID-19): The importance of recognising possible early ocular manifestation and using protective eyewear. Br J Ophthalmol 2020;104: 297-298. DOI:10.1136/bjophthalmol-2020-315994.

5. Yu X, Yang R. COVID-19 transmission through asymptomatic carriers is a challenge to containment. Influenza Other Respi Viruses . 2020;00:1-2.

6. Feng S, Shen C, Xia, N, et al . Rational use of face masks in the COVID-19 pandemic. Lancet Respir Med 2020 https://doi.org/10.1016/ S2213-2600(20)30134-X.

7. Johnson DF, Druce JD, Birch C, Grayson ML. A Quantitative Assessment of the Efficacy of Surgical and N95 Masks to Filter Influenza Virus in Patients with Acute Influenza Infection. Clinical Infectious Diseases 2009; 49: 275-277 DOI: 10.1086/600041.

8. Greenhalgh T, Schmid, MB, Czypionka T, et al. Face masks for the public during the covid-19 crisis. BMJ , 2020;369:m1435 DOI: https://doi.org/10.1136/bmj.m1435.

\section{Hosted file}

Prisoner_dilemma_wearing_masks_letter_to_the_editor_table.docx available at https: //authorea.com/users/321547/articles/450775-do-we-experience-a-prisoner-s-dilemma-whenchoosing-to-wear-a-face-mask 